\title{
24-Methylenecycloartanyl Ferulate Induces PPAR- $\gamma 2$ Mediated Regulation of Angiogenesis-related Genes and Inhibits Akt/mTOR Signaling
}

Jung Bong Kim ${ }^{1 \dagger}$, Grace Kelly Lee ${ }^{2 \dagger}$, Hae-Yeong Kim³ ${ }^{3}$, Heon Woong Kim ${ }^{1}$, Hwan Hee Jang ${ }^{1}$, Young Mok Yang ${ }^{4}$, Seon Hye Lee ${ }^{1}$, Sung Hyen Lee ${ }^{1}$, and Jong Hwan Park ${ }^{5 *}$

${ }^{1}$ National Institute of Agricultural Sciences (NIAS), RDA 166 Nongsaengmyeong-ro, Iseomyeon, Wanju-gun, Jellabuk-do, 55365, South Korea; jungbkim@korea.kr (J.B.K.); glgkglgk0202@naver.com (S.H.L.); ksharrier@korea.kr (H.W.K.); 1shin@korea.kr (S.H.L.); rapture19@korea.kr

${ }^{2}$ Chingchai Wanidworanun, MD PLLC, $40019^{\text {th }}$ St N Suite 228 Arlington, VA 22203, USA; leegracek3@gmail.com

${ }^{3}$ Institute of Life Science \& Resources and Department of Food Science \& Biotechnology, Kyung Hee University, Yongin 446-701, South Korea; hykim@khu.ac.kr

${ }^{4}$ Department of Pathology, School of Medicine, Institute of Biomedical Science and Technology, Konkuk University, Seoul 05029, South Korea; ymyang@kku.ac.kr ${ }^{5 *}$ Inha University College of Medicine, 27 Inhang-Ro, Jung Gu, Incheon 400-103, South Korea; nihpark@yahoo.com

\footnotetext{
* Author to whom correspondence should be addressed.

${ }^{\dagger}$ These authors equally contributed to this study.
} 


\begin{abstract}
We investigated the effect and molecular mechanism of 24-MCF-induced PPAR- $\gamma 2$ on angiogenesis-related genes in MCF7 cells. cDNA microarray, semi-quantitative reverse transcription (RT)-PCR, and western blotting revealed that 24-MCF mediated the expression of genes related to angiogenesis in MCF-7 cells. Luciferase reporter assay demonstrated that promoter activation of the LIF gene, an anti-angiogenesis factor, was increased upon PPAR- $\gamma 2$ overexpression and 24-MCF treatment, whereas activation of HoxA7 and VEGF promoters, known pro-angiogenesis factors, decreased upon PPAR- $\gamma 2$ overexpression and 24-MCF treatment. We identified PPAR-response elements (PPRE) located in the VEGF $(-913$ to +1$)$, HoxA7 (-1107 to +1$)$, and LIF promoter regions (-9032 to -8403). VEGF promoter activity was abolished by mutation of the PPRE motif. Treatment with 24-MCF inhibited expression of VEGF and inhibited the Akt/mTOR pathway. Treatment with 24-MCF also decreased VEGF secretion in MCF7 cells and PMA-stimulated tube formation in HUVECs. Our findings suggest that 24-MCF induces PPAR- $\gamma 2$-mediated regulation of anti-angiogenesis via PPRE motifs in VEGF, HoxA7, and LIF promoters or upstream regions. Furthermore, 24-MCF treatment inhibits angiogenesis by blocking VEGF secretion.
\end{abstract}

Keywords: 24-methylenecycloartanyl ferulate, angiogenesis, PPAR- $\gamma 2$, PPRE, Akt/mTOR, HoxA7, VEGF, LIF, HUVEC.

\title{
1. Introduction
}

24-Methylenecycloartanyl ferulate (24-MCF), a gamma oryzanol ( $\gamma$-oryzanol) compound, is a non-toxic dietary compound that exhibits important pharmacological activities, such as anticholesterol [1, 2], anti-platelet aggregation [3], and anti-tumor properties [4, 5, 6]. Our previous studies showed that 24-MCF-induced peroxisome proliferator-activated receptor-gamma 2 (PPAR- $\gamma 2$ ) activation increased parvin- $\beta$ expression, leading to the inhibition of oncogenic integrin-linked kinase that is associated with tumor angiogenesis signaling in MCF7 cells [4].

PPAR represents a nuclear hormone receptor superfamily of ligand-inducible transcription factors that regulate genes in various metabolic processes. The PPAR family comprises three isoforms: PPAR $\alpha, \operatorname{PPAR} \beta / \delta$, and PPAR $\gamma$ [7]. Activated PPAR $\alpha$ regulates genes involved in the $\beta$-oxidation pathway $[8,9], \operatorname{PAAR} \beta / \delta$ enhances glucose metabolism, and 
activation of PPAR $\gamma$ causes insulin sensitization and enhances glucose metabolism [10]. Three different isoforms of PPAR $\gamma$ have been identified and were generated as a result of alternative splicing: PPAR $\gamma 1$, PPAR- $\gamma 2$, and PPAR- $\gamma 3$ [11]. PPAR- $\gamma 2$ is expressed exclusively in adipose tissue and accelerates adipocyte differentiation [12]. A potential role for PPAR $\gamma$ in carcinogenesis was highlighted by the ability of the ligands to affect cellular proliferation and differentiation [13]. Because of its potent effects on the regulation of cell fate, PPAR $\gamma$ has attracted interest as a potential target for cancer therapy [7]. Furthermore, numerous studies have shown that PPAR $\gamma$ activation leads to the regulation of anti- and pro-angiogenic pathways [14, $15]$.

Although several key components of the angiogenesis process and the angiogenic switch have been reported [17, 18, 19], the complete underlying molecular mechanisms are not fully known. Previous studies showed that the promoter sequence of the pro-angiogenic factor VEGF contains a PPAR response element (PPRE) motif $[16,20]$ and demonstrated that PPAR $\gamma$ activation decreases pro-angiogenic VEGF [14, 15]. The PI3K/Akt/mTOR pathway also modulates the expressions of pro-angiogenic factors, such as VEGF and angiopoietins [21]. Numerous inhibitors targeting the PI3K/Akt/mTOR pathway have been identified in plants and food sources [17, 22], and these compounds have been shown to decrease VEGF secretion and angiogenesis [17, 22]. Although 24-MCF has recently been shown to possess anti-tumor properties $[4,5,6]$, its molecular mechanism is not fully understood and its potential effects on angiogenesis have remained largely unknown.

In this study, we hypothesized that PPAR- $\gamma 2$ regulates 24-MCF-mediated angiogenesis. We first examined whether angiogenesis-related genes identified by microarray in MCF-7 cells treated with 24-MCF are PPAR- $\gamma 2$ target genes. We also evaluated whether 24-MCF treatment activates the Akt/mTOR pathway.

\section{Materials and Methods}

\subsection{Materials}

The rice bran compound 24-MCF was provided by the Korean National Institute of Crop Science (Jeollabuk-do, Korea). Each gene on the array Agilent Human Whole Genome 44K v2 chip was provided by E-Biogen Inc. (Seoul, Korea). Total RNA was extracted from human breast cancer 
MCF7 cells using a TRIzol reagent kit (Invitrogen, San Diego, CA) following the manufacturer's instructions. Antibodies against phospho-Akt (Ser 473), Akt, phospho-mTOR (Ser 2448), and mTOR were purchased from Cell Signaling Technology (Beverly, MA). Hypoxia-inducible factor (HIF)-1 $\alpha$, HIF-1 $\beta$, PPAR- $\gamma 2$, VEGF and $\beta$-actin antibodies were purchased from Santa Cruz (Santa Cruz, CA).

\subsection{Cell culture}

Human breast cancer MCF7 cells were cultured in Dulbecco's Modified Eagle's Medium (HyClone, Logan, UT) supplemented with 10\% heat-inactivated fetal bovine serum (HyClone, Logan, UT), $100 \mathrm{U} / \mathrm{ml}$ penicillin, and $100 \mu \mathrm{g} / \mathrm{ml}$ streptomycin in $5 \% \mathrm{CO}_{2}$ at $37^{\circ} \mathrm{C}$. Human umbilical vein endothelial cells (HUVECs; Lonza, Walkersville, MD) were cultured in EBM-2 medium supplemented with EGM-2 Single Quots. EBM-2 and EGM-2 Single Quots were purchased from Cambrex Company (Lonza, Walkersville, MD).

\subsection{Plasmid constructs}

We collected the putative PPRE motifs using the GeneCards (www.genecards.org) and Dragon PPAR Response Element Spotter v.2.0 (www.cbrc.kaust.edu.sa/ppre/). To construct promoterreporter plasmids, promoter fragments containing PPRE motifs were amplified and ligated into the SacI and Hind III sites of the pGL3-Basic vector, which contains firefly luciferase coding sequences but lacks eukaryotic promoter or enhancer elements.

Oligonucleotides used in this experiment were as follows: VEGF $(-913$ to +1$)$ were 5'- GCAC ATTGTCAGAGGGACACACTGTGGCCC-3' (forward) and 5'-CTCTGTCCAGAGAC ACGCGCCCGCGGGGCA-3' (reverse); LIF (-9032 to -8403) were 5'-AGGCGATGAC

TGGGCAGCCCTCCGCAT-3' (forward) and 5'-CTCCCAGCTGTGACAAAGATTCCCTGG-3' (reverse); and HoxA7 (-1107 to +1) were 5'-GGATCCAGACGGGGAAGGCGCAGCATCTCT3' (forward) and 5'- GGGAGGAGACAGCCCAGCGCCCACCTGCCC-3' (reverse).

Mutation of the PPRE motifs in the VEGF promoter, which abolishes the PPAR- $\gamma 2$ binding site, was constructed by a 5-bp substitution (5'-GGAGAAGGCCAG aaGctt CTCCAGG, underlined). Construction of pcDNA-human PPAR- $\gamma 2$ (accession No. NM_015869) expression plasmid was described previously [4]. Plasmids were confirmed by DNA sequencing. 


\subsection{Microarray}

Microarrays were generated and cRNA probes were hybridized using the Low RNA Input Linear Amplification Kit (Agilent Technology, Santa Clara, CA) according to the manufacturer's instructions. Labeled cRNA was purified on a cRNA Cleanup Module (Agilent Technology, Santa Clara, CA) according to the manufacturer's instructions. Fragmented cRNA was resuspended with $2 \times$ hybridization buffer and directly pipetted onto the assembled Human Oligo Microarray (44K; Agilent Technology). Arrays were hybridized at $65^{\circ} \mathrm{C}$ for $17 \mathrm{~h}$ using a hybridization oven (Agilent Technology, Santa Clara, CA). Hybridized microarrays were washed according to the manufacturer's protocol (Agilent Technology).

\subsection{Data analysis}

Hybridized images were scanned using a DNA microarray scanner (Agilent Technology, Santa Clara, CA) and quantified with Feature Extraction software (Agilent Technology). All data normalization and selection of genes whose expression changed were performed using GeneSpring GX 7.3 (Agilent Technology). The averages of normalized ratios were calculated by dividing the average of the normalized signal channel intensity by the average of the normalized control channel intensity. Functional annotation of genes was performed according to the Gene Ontology Consortium (http://www.geneontology.org/index.shtml) using Gene Spring GX 7.3. Genes were classified based on searches performed by BioCarta (http://www.biocarta.com/), GenMAPP (http://www.genmapp.org/), DAVID (http://david.abcc.ncifcrf.gov/), and Medline (http://www.ncbi.nlm.nih.gov/).

\subsection{Western blot analysis}

Western blot analysis was performed according to a standard method as previously described [4]. Protein samples $(20 \mu \mathrm{g})$ were separated on a 4-12\% NuPAGE gel (Invitrogen, San Diego, CA) and then transferred to a nitrocellulose membrane using standard procedures. The membrane was blotted with primary antibodies or anti- $\beta$-actin antibody as a control and analyzed using the Multi Gauge V3.1 program (Fujifilm Tokyo, Japan).

\subsection{RNA isolation and quantitative reverse transcription (RT)-PCR analysis}

Total RNA was isolated using TRIzol reagent (Invitrogen, San Diego, CA) according to the 
manufacturer's protocol. Total RNA $(1 \mu \mathrm{g})$ was converted to cDNA using oligo-dT primer and AccuPower RT premix (Bioneer, Korea) in a $20 \mu \mathrm{l}$ reaction. PCR reactions were performed using the AccuPower PCR Mix (Bioneer, Korea) and primers (see Table 1 for primer sequences). PCR was performed at an annealing temperature of $55-58^{\circ} \mathrm{C}$ for $25-30$ cycles. The amplified PCR products were run on a 2.0\% agarose gel and visualized using ethidium bromide (Sigma, St. Louis, MO).

Table 1. Forward and reverse primer sequences of mRNAs for RT-PCR analysis

\begin{tabular}{|c|c|c|c|c|}
\hline No. & Gene & Accession No. & Sequence $\left(5^{\prime} \rightarrow 3^{\prime}\right)$ & roduct Size (bp) \\
\hline 1 & NPPB & NM_002521 & $\begin{array}{l}\text { F-GCTTTCCTGGGAGGTCGTT } \\
\text { R-CTGATCCGGTCCATCTTCCT }\end{array}$ & 305 \\
\hline 2 & LIF & NM_002309 & $\begin{array}{l}\text { F-ACCTGGACAAGCTATGTGGC } \\
\text { R-CTTCCCCAGGAGTTGACAGC }\end{array}$ & 341 \\
\hline 3 & EGR1 & NM_001964 & $\begin{array}{l}\text { F-GGCCCTCAATACCAGCTACC } \\
\text { R-TCGCTCCTGGCAAACTTTCT }\end{array}$ & 312 \\
\hline 4 & HOXA7 & NM_006896 & $\begin{array}{l}\text { F-TATCAGAGCCCCTTTGCGTC } \\
\text { R-TTAATCTGGCGCTCGGTGAG }\end{array}$ & 341 \\
\hline 5 & Lleam & NM_024003 & $\begin{array}{l}\text { F-GAGTAGGGCACAGCTCTTGG } \\
\text { R-CCTCAGGTGTGACCACAGTC }\end{array}$ & 332 \\
\hline 6 & MMP11 & NM_005940 & $\begin{array}{l}\text { F-ACACCTTTCGCTACCCACTG } \\
\text { R-TTCACCGTCGTACACCCAG }\end{array}$ & 395 \\
\hline 7 & RHOT1 & XM_011524969 & $\begin{array}{l}\text { F-CTTGCAATACTGCTGATGCCC } \\
\text { R-GATTGCAGCAAGTCTGAGTTGAG }\end{array}$ & 250 \\
\hline 8 & $\mathrm{Pbx1}$ & XM_005245228 & $\begin{array}{l}\text { F-GATGATCCTGCGTTCCCGAT } \\
\text { R-GAACTGGAAGAACCAGCCGA }\end{array}$ & 342 \\
\hline 9 & VEGF & NM_001025366 & $\begin{array}{l}\text { F-CTGCTGTCTTGGGTGCATTG } \\
\text { R-TCACCGCCTCGGCTTGTCACA }\end{array}$ & 690 \\
\hline 10 & PPAR- $\gamma 2$ & XM_011533842 & $\begin{array}{l}\text { F-GCGATTCCTTCACTGATAC } \\
\text { R-GCATTATGAGACATCCCCAC }\end{array}$ & 580 \\
\hline 11 & GAPDH & NM_002046 & $\begin{array}{l}\text { F-GGATTTGGTCGTATTGGG } \\
\text { R-GAAGATGGTGATGGGATT }\end{array}$ & 204 \\
\hline
\end{tabular}




\subsection{Luciferase assay}

MCF7 cells were seeded in 24-well plates 12-16 h before transfection. Cells were transfected using Lipofectamine LTX (Invitrogen, San Diego, CA) according to the manufacturer's instruction with the following plasmids: $500 \mathrm{ng}$ of reporter plasmid (VEGF, HoxA7, or LIF), 50 ng of pRL-TK (Promega, Madison, WI), and either $500 \mathrm{ng}$ of pcDNA or pcDNA-PPAR- $\gamma 2$. Twenty-four hours later, cells were incubated with a medium containing dimethyl sulfoxide (DMSO) or 24-MCF $(25,50$, and $100 \mu \mathrm{M})$. After $24 \mathrm{~h}$, both firefly and Renilla luciferase activities were quantified using a Dual-Luciferase Reporter Assay system (Promega, Madison, WI) according to the manufacturer's instructions. Relative luciferase activity was calculated as the ratio of firefly /Renilla activity. All experiments were performed in triplicate.

\subsection{Quantification of VEGF protein}

VEGF was quantified using the Quantikine human VEGF enzyme-linked immunosorbent assay (ELISA) kit (R\&D Systems, Minneapolis, MN) according to the manufacturer's instructions. Briefly, MCF7 cells were seeded in 12-well plates and cultured until 90\% confluent. Cells were switched to fresh serum-free medium containing 24-MCF. After $12 \mathrm{~h}$, the conditioned medium was collected and the number of cells in each well was counted. The secretion of VEGF in the conditioned medium $(200 \mu \mathrm{l})$ was determined and normalized against the number of cells in the well. A serial dilution of human recombinant VEGF was performed in each assay to obtain a standard curve. All experiments were performed in triplicate.

\subsection{Tube formation assays}

Endothelial tube formation was assessed by an in vitro cell-based assay (Cayman Chemical, Ann Arbor, MI) in HUVECs according to the manufacturer's instructions. Phorbol 12-myristate 13acetate (PMA) pretreatment enhanced the ability of HUVECs to organize into cell networking structure (termed tube formation). A suspension of HUVECs in medium was then seeded in 96well plates coated with cell-based extracellular matrix gel at a density of $10^{5}$ cells $/ \mathrm{ml}$ and treated with 24-MCF in the presence of $1 \mu \mathrm{M}$ PMA. After $12 \mathrm{~h}$, tube formation was observed by calcein staining under an inverted fluorescence microscope (Olympus IX71, Tokyo, Japan). 


\subsection{Statistical analyses}

All data were evaluated by a one-way analysis of variance (ANOVA). A P-value of $<0.05$ was considered to be statistically significant.

\section{Results}

\subsection{Gene expression profiles of 24-MCF-treated MCF7 cells}

We analyzed changes in global gene expression profiles in MCF7 cells treated with 24-MCF $(100 \mu \mathrm{M})$ and those treated with DMSO using a microarray and identified 30,552 differentially expressed genes out of the 44,000 arrayed genes $(69.4 \%)$ by microarray hybridization (Supplementary 1. xls). Genes with a fold change of 2.0 or above were considered positively regulated, whereas those with a fold change of 0.5 or below were considered negatively regulated. Figure 1A shows a scatter plot representing the average $\log _{2}$-fold changes; a total of 914 upregulated and 642 downregulated genes were identified in MCF7 cells treated with 24MCF. Quantitatively, unmodified genes by an average log2-fold change of $\leq 2.0$ or $\geq-0.5$ were assigned a rate of $94.9 \%$ (Figure 1A). Scatter plot analyses showed 5.1\% (1,556 genes) of the differentially expressed under 24-MCF treatment. To examine the biological functions affected by 24-MCF treatment, we performed functional annotation clustering analysis of the differentially expressed genes using the Gene Ontology Consortium program. The differentially expressed genes were associated with inflammation, angiogenesis, extracellular matrix, immune response, cell proliferation, and cell migration (Figure 1B), indicating that several cellular metabolic pathways are linked directly or indirectly to the response to 24-MCF treatment. 
A

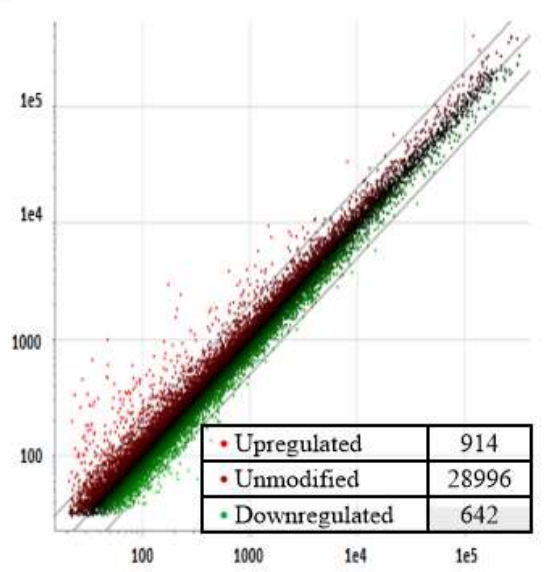

B

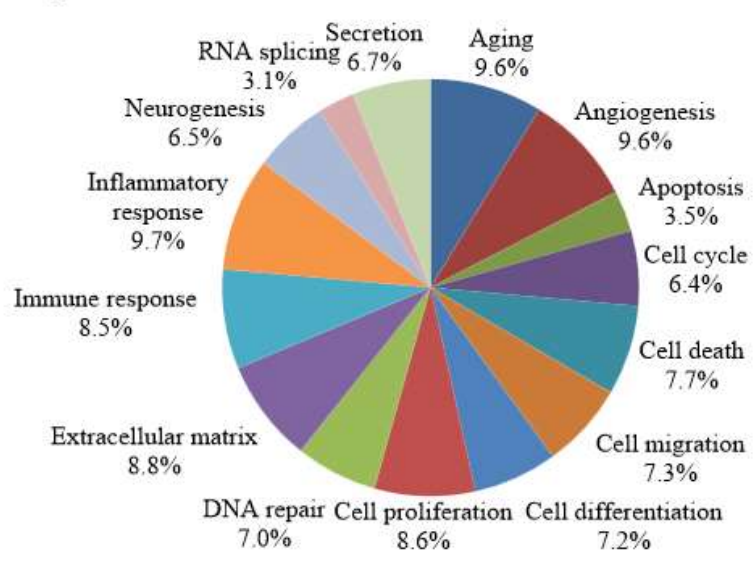

Figure 1. cDNA microarray analysis of gene expression in MCF-7 cells in response to 24-MCF.

(A) Scatter plot of normalized microarray data for all 44,000 genes. Plot showing the upregulated (2.0-fold or above, red), unmodified (black), and downregulated genes ( 0.5 or below, green) in MCF7 cells treated with 24-MCF. (B) Diagram chart showing distribution of ontological analysis in MCF7 cells treated with 24-MCF. Gene ontology terms of differentially expressed genes are shown; the numbers of genes in each category are indicated as a percentage.

\subsection{Validation of microarray data using RT-PCR}

From the functional annotation clustering analysis, we then selected 15 genes in the angiogenesis categorization that were differentially expressed. Genes with fold change $>2$ are upregulated and genes with fold change $<0.5$ are downregulated in the MCF7 cells treated with 24-MCF (Figure 2A). Table 2 provides further characterization of 10 of the 15 genes that were more strictly responsive to 24-MCF; literature search for these genes classified them as anti- and proangiogenesis related genes based on their reported functions. For validation of 10 genes that were differentially expressed among all genes in the angiogenesis category, we next analyzed expression levels of these genes using RT-PCR with the primers listed in Table 1. These results showed that at $12 \mathrm{~h}$ after 24-MCF treatment, anti-angiogenesis-related genes (LIF, NPPB, PPAR- $\gamma 2$, and EGR1 genes) were significantly upregulated, whereas pro-angiogenesis-related genes (HoxA7, L1Cam, MMP11, RHOT1, VEGF, and Pbx1 genes) were markedly downregulated in MCF7 cells (Figure 2B). Furthermore, these effects occurred in a dose- 
dependent manner. These findings help validate the microarray results. Consistent with our previous study, we observed a significant increase in the expression of PPAR- $\gamma 2$ in MCF7 cells treated with 24-MCF in a dose-dependent manner [4] (Figure 2B), indicating that 24-MCF treatment elevates PPAR- $\gamma 2$ expression and shifts the angiogenic switch towards a state of antiangiogenesis.

A

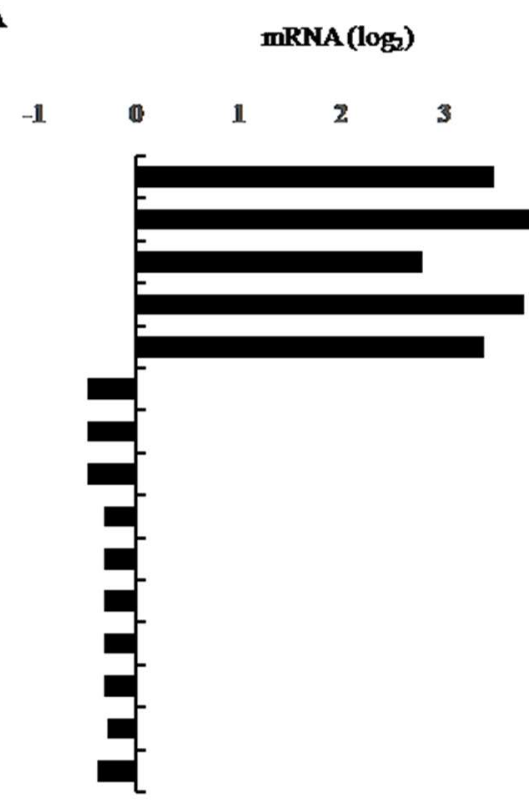

B

\begin{tabular}{|c|c|c|c|c|}
\hline \multicolumn{4}{|c|}{ 24-MCF ( $\mu M)$} & \\
\hline DMSO & 25 & 50 & 100 & \\
\hline & 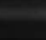 & & & LIF \\
\hline & & & & NPPB \\
\hline & & & & EGR1 \\
\hline & 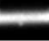 & & & PPAR- $\gamma 2$ \\
\hline & 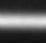 & 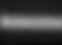 & 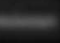 & MMP11 \\
\hline & & $=$ & & L1cam \\
\hline & & - & & Pbx1 \\
\hline & 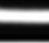 & 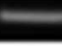 & & HOXA7 \\
\hline & & 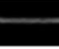 & & RHOT1 \\
\hline & & - & & VECF \\
\hline & & & & TA \\
\hline
\end{tabular}

Figure 2. RT-PCR verification of microarray results.

(A) A list of the top 15 genes from the array data with the greatest differences in expression between MCF7 cells treated with 24-MCF and DMSO. (B) Semi-quantitative PCR analysis of 10 selected genes among the 15 genes listed (Figure 2A) in MCF7 cells treated with various concentrations of 24-MCF as indicated or DMSO. GAPDH mRNA levels served as control.

\subsection{PPAR- $\boldsymbol{2} 2$ modulates the promoter activity of angiogenesis-related genes via PPRE motif} We hypothesized that the PPAR- $\gamma 2$ transcription factor is involved in regulating 24-MCFmediated angiogenesis. To determine whether PPAR- $\gamma 2$ regulates the angiogenesis-related genes identified in the microarray, we performed luciferase assays using promoter sequences from three of the identified genes. We constructed luciferase reporter plasmids driven by promoter sequences from VEGF (-914/+1) and HoxA7 (-1107/+1), both known pro-angiogenic genes that 
were identified as downregulated genes in the microarray (Figure $3 \mathrm{~A}$ and $3 \mathrm{~B}$ ). We transfected the VEGF and HoxA7 reporter plasmids together with the pcDNA3-PPAR- $\gamma 2$ expression plasmid or the vector plasmid (pcDNA3) into MCF7 cells and performed luciferase assays. As shown in Figures 3A and 3B, we observed that activation of the VEGF and HoxA7 promoter was significantly decreased in comparison with the control $(\mathrm{p}<0.05)$.

Table 2. Angiogenesis-related genes identified by microarray and their proposed functions

\begin{tabular}{|c|c|c|c|}
\hline $\begin{array}{l}\text { Gene } \\
\text { symbol }\end{array}$ & Gene name & Function/activities & Refs \\
\hline \multicolumn{4}{|c|}{ Anti-angiogenesis-related genes } \\
\hline LIF & $\begin{array}{l}\text { Leukemia inhibitory } \\
\text { factor }\end{array}$ & $\begin{array}{l}\text { Angiogenesis inhibitor that may interfere with VEGF and } \\
\text { bFGF }\end{array}$ & 36 \\
\hline NPPB & Natriuretic peptide B & $\begin{array}{l}\text { Angiogenesis inhibitor that may interfere with MAP kinase } \\
\text { pathway }\end{array}$ & 37,38 \\
\hline EGR1 & $\begin{array}{l}\text { Early growth response } \\
\text { protein-1 }\end{array}$ & Inhibits angiogenic signaling of VEGF and bFGF & 39 \\
\hline PPAR $\gamma 2$ & $\begin{array}{l}\text { Peroxisome } \\
\text { proliferator-activated } \\
\text { receptor gamma2 }\end{array}$ & $\begin{array}{l}\text { Causes insulin sensitization and enhances glucose } \\
\text { metabolism. } \\
\text { Inhibits angiogenesis and cancer }\end{array}$ & $\begin{array}{l}4,7,8, \\
9,10, \\
14,15\end{array}$ \\
\hline \multicolumn{4}{|c|}{ Pro-angiogenesis-related genes } \\
\hline HoxA7 & Homeobox A7 & $\begin{array}{l}\text { Stimulates cell migration, proliferation, and differentiation. } \\
\text { Induces angiogenesis in hMSCs }\end{array}$ & 40,41 \\
\hline L1cam & $\begin{array}{l}\text { L1 cell adhesion } \\
\text { molecule }\end{array}$ & Induces angiogenesis signaling & 42,43 \\
\hline MMP11 & $\begin{array}{l}\text { Matrix } \\
\text { metalloproteinase } 11\end{array}$ & $\begin{array}{l}\text { Stimulates tumor growth, angiogenesis, invasion and } \\
\text { metastasis }\end{array}$ & 44 \\
\hline RHOT1 & $\begin{array}{l}\text { Ras homology family } \\
\text { member T1 }\end{array}$ & Stimulates tumor growth and angiogenesis & 45,46 \\
\hline $\mathrm{Pbx} 1$ & $\begin{array}{l}\text { Pre-B-cell leukemia } \\
\text { transcription factor-1 }\end{array}$ & $\begin{array}{l}\text { Anti-sense against Pbx1 impairs endothelial cell migration } \\
\text { and blocks angiogenesis induced by bFGF in vivo }\end{array}$ & 47 \\
\hline VEGF & $\begin{array}{l}\text { Vascular endothelial } \\
\text { growth factor }\end{array}$ & $\begin{array}{l}\text { Stimulates tumor growth, migration, invasion, } \\
\text { angiogenesis, and tube formation }\end{array}$ & $\begin{array}{c}33,34 \\
35\end{array}$ \\
\hline
\end{tabular}

To analyze whether the transcriptional regulation of the VEGF promoter by PPAR- $\gamma 2$ is mediated by its interaction with the PPRE motif, we constructed a mutant VEGF reporter vector with a 5-bp substitution in the PPRE (GGGTCA to aaGctt). As shown in Figure 3A, the PPAR$\gamma 2$-mediated activation of the PPRE mutant vector was abolished compared with wild-type $(\mathrm{p}<0.05)$, indicating that the PPRE motif is critical for PPAR- $\gamma 2$-mediated transcriptional induction of VEGF.

We also performed luciferase assays using the promoter sequence of LIF (-9032 / -8403), 
an anti-angiogenic gene that was identified as an upregulated gene in the microarray (Figure 3E). We observed that the activation of the LIF reporter vector by PPAR- $\gamma 2$ expression was significantly increased in comparison with the control (no PPAR- $\gamma 2$ expression and DMSO) $(\mathrm{p}<0.05)$ (Figure 3C), indicating that PPAR- $\gamma 2$ could be a key regulator of the anti-angiogenic balance in angiogenesis.
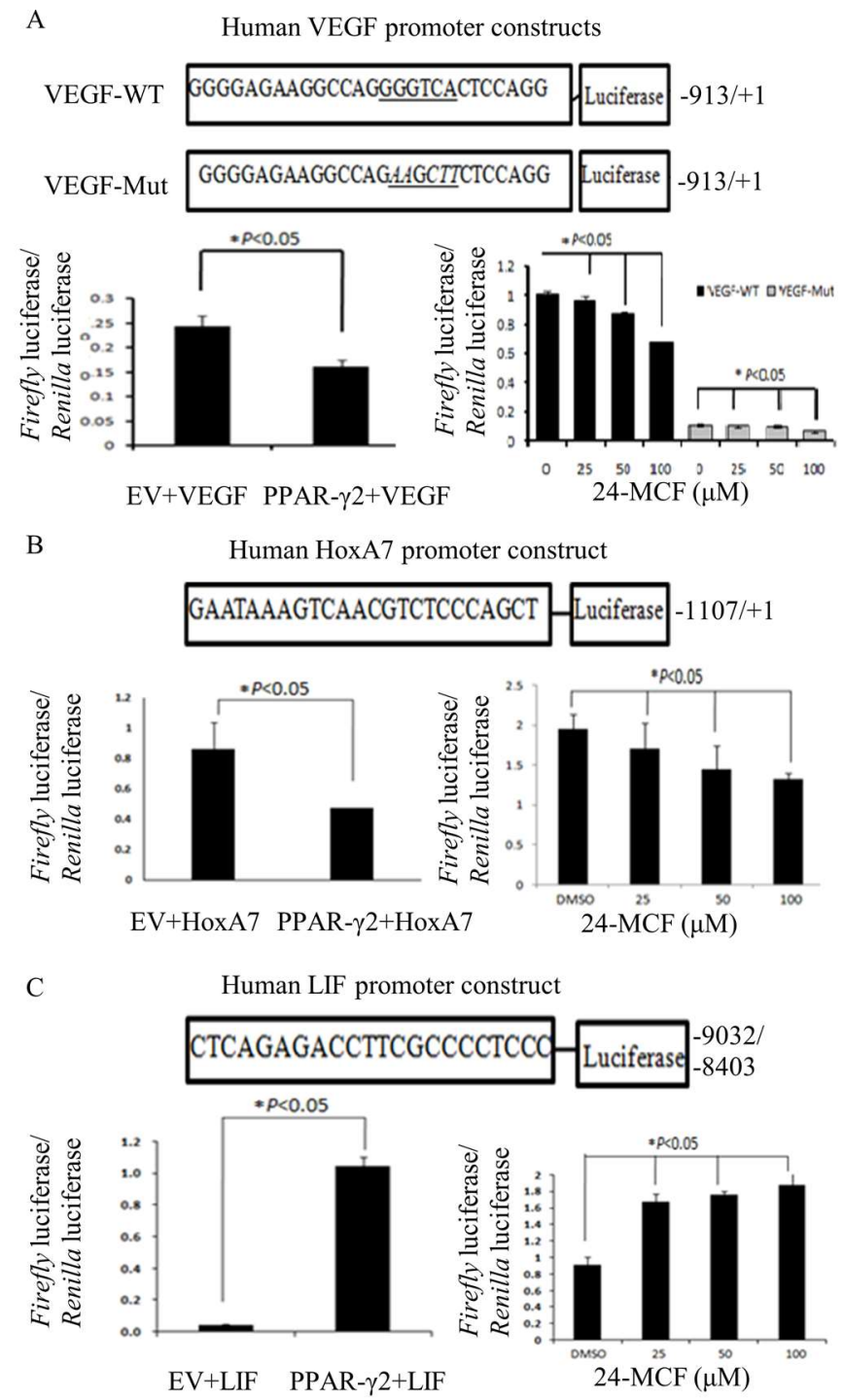

Figure 3. PPAR- $\gamma 2$ modulates promoter activity via PPRE motifs.

(A, B, C) Schematic representations of the (A) VEGF promoter $(-913 /+1)$; the mutant constructs contained a 5-bp substitution in the PPRE (GGGTCA to aaGctt). (B) HoxA7 promoter $(-1107 /+1)$ and (C) LIF (-9032/-8403) promoters containing a PPRE motif. Promoter regions were inserted 
into luciferase plasmids. (A, B, C) MCF7 cells were co-transfected with the (A) VEGF, (B) HoxA7, or (C) LIF reporter plasmid (500 ng), pRL-TK (50 ng) and pcDNA3-PPAR- $\gamma 2$ or empty vector (EV). Luciferase activities were normalized by Renilla luciferase (pRL-TK) activity. Values represent as fold induction of the control. ${ }^{*} p<0.05$ compared with the control.

\subsection{4-MCF inhibited VEGF activation and inhibited the Akt/mTOR pathway}

Our previous study demonstrated that the 24-MCF compound inhibited Akt kinase activity [4]. To determine whether 24-MCF treatment could inhibit VEGF activation by affecting the Akt/mTOR pathway in MCF-7 cells, we first investigated activation of p-Akt and p-mTOR in 24-MCF-treated MCF-7 cells by western blotting. As shown in Figure 4A, 24-MCF treatment inhibited the levels of p-Akt (Ser 473), concomitant with inhibition of p-mTOR (Ser 2448) in MCF7 cells in a dose-dependent manner, although it had no effect on total Akt and mTOR protein levels. Treatment with 24-MCF also leads to effects on expression of both HIF-1 $\alpha$ and VEGF protein, with no effects on HIF-1 $\beta$ (Figure. 4A). To further determine whether 24-MCF treatment inhibited VEGF secretion, we measured the secretion of VEGF using ELISA. As shown in Figure 4B, 24-MCF treatment gradually decreased secretion of VEGF in MCF7 cells in a dose-dependent manner $(\mathrm{p}<0.05)$, indicating that $24-\mathrm{MCF}$ treatment is impacting VEGF secretion. 
A
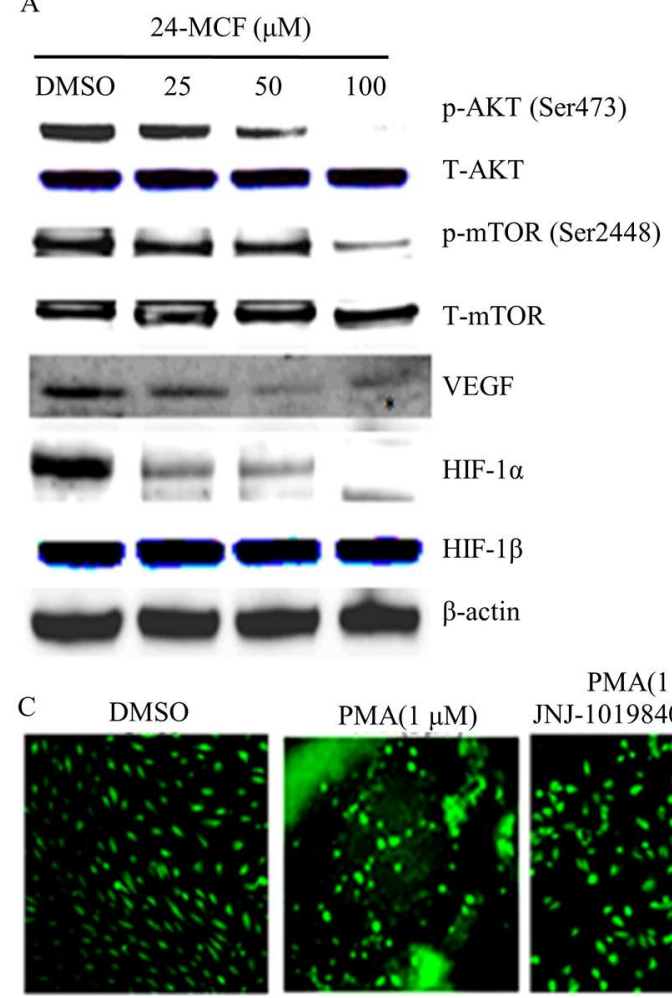
PMA $(1 \mu \mathrm{M})$

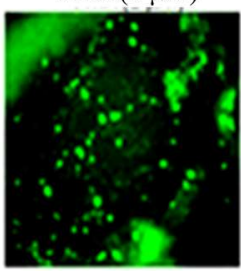

B

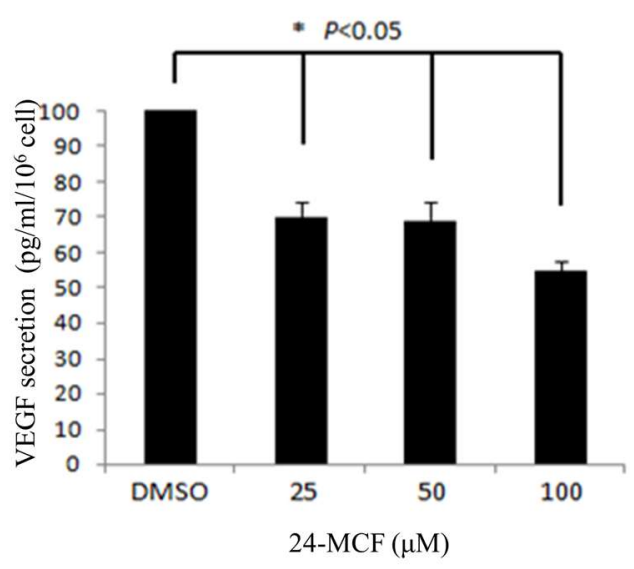

$\operatorname{PMA}(1 \mu \mathrm{M})$ JNJ-10198409 $(1 \mu \mathrm{M})$
$\operatorname{PMA}(1 \mu \mathrm{M})$ 24-MCF $(25 \mu \mathrm{M})$

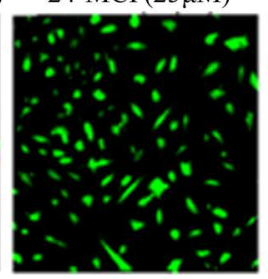

$\operatorname{PMA}(1 \mu \mathrm{M})$ 24-MCF $(100 \mu \mathrm{M})$

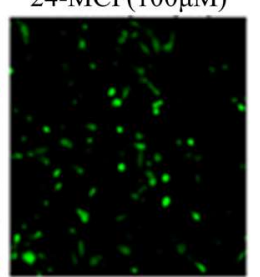

Figure 4. 24-MCF inhibited VEGF secretion via the Akt/mTOR pathway and HUVEC tube formation

(A) MCF-7 cells were treated with 24-MCF $(0,25,50$, and $100 \mu \mathrm{M})$ for $24 \mathrm{~h}$ and analyzed by western blotting using the indicated primary antibodies. $\beta$-actin served as loading control. (B) VEGF secretion levels in the supernatant were determined in the presence or absence of 24-MCF using ELISA and normalized against the number of cells in the well. A serial dilution of human recombinant VEGF was performed in each assay to obtain a standard curve. All experiments were performed in triplicate. ${ }^{*} p<0.05$ compared with DMSO control.

(C) HUVECs were kept in 1\% FBS containing medium for $12 \mathrm{~h}$. Tube formation on matrigel was performed using HUVECs treated with $1 \mu \mathrm{M}$ phorbol-12-myristate-13-acetate (PMA), 24MCF $(25$ or $100 \mu \mathrm{M})$ and/or JNJ-10198409 $(1 \mu \mathrm{M})$ as indicated. Tube formation was observed by calcein staining under an inverted fluorescence microscope (Olympus IX71, Tokyo, Japan). 


\subsection{4-MCF inhibited tube formation in HUVECs}

To determine whether 24-MCF treatment exhibits anti-angiogenic activity, we performed tube formation assays in HUVEC cells using an in vitro cell-based assay. Tube formation was induced by $1 \mu \mathrm{M}$ PMA [33], which enhances the ability of HUVEC cells to undergo tube formation (Figure 4). HUVECs were treated with 25 or $100 \mu \mathrm{M}$ 24-MCF for $12 \mathrm{~h}$ and then tube formation was observed by calcein staining under an inverted fluorescence microscope. Treatment of HUVECs with an angiogenic agent (1 $\mu \mathrm{M}$ JNJ-10198409), a PDGF-BB tyrosine kinase inhibitor, successfully decreased tube formation (Figure 4). Importantly, we found that 24-MCF treatment (25 and $100 \mu \mathrm{M})$ treatment decreased tube formation in comparison with HUVECs treated with PMA alone in Matrigel. Together these results indicate that 24-MCF treatment exhibits anti-angiogenic activity.

\section{Discussion}

Angiogenesis is the formation of new blood vessels and is a hallmark of tumor development and metastasis [23]. In particular, PPAR $\gamma$ targets a set of genes that have a critical impact on numerous diseases including angiogenesis and cancer $[24,25]$. PPAR $\gamma$ activation also inhibits angiogenesis by blocking ELR $+\mathrm{CXC}$ chemokine secretion, which is mediated through antagonizing NF- $\kappa \mathrm{B}$ activation in non-small cell lung cancer (NSCLC) [26]. Our previous results show that 24-MCF-induced PPAR- $\gamma 2$ increases parvin- $\beta$ expression, which inhibits oncogenic ILK signaling, anchorage-independent growth, and cell migration [4]. A recent study established PPARs as a group of ligand-activated transcriptional regulators that sit at the intersection of genes and the dietary environment [27]. Thus, PPAR $\gamma$ has shown predominately anti-angiogenic properties in vitro and in animal models [27]. Therefore, some research has examined the PPAR $\gamma$ activating potential of a wide range of natural products originating from traditionally used medicinal plants and dietary sources [17]. The $\gamma$-oryzanol compound 24-MCF has been reported to have important pharmacological activities, including anti-tumor properties $[4,28]$. It has nontoxicity and is used as a healthy food supplement [4]. Nonetheless, its mechanism is unclear. In addition, 24-MCF induced gene expression changes have not been fully recognized until now.

Here we identified differentially expressed genes in MCF7 cells treated with 24-MCF using a microarray technique. We found that the genes differentially expressed in response to 24- 
MCF treatment were involved in various cellular responses, including the inflammatory response, angiogenesis, aging, extracellular matrix, cell proliferation, immune response, cell death, and cell migration. Based on the clustering results, we selected the most significantly angiogenesisrelated genes, including five anti-angiogenesis-related genes that were upregulated (NPPB, LIF, PPAR- $\gamma 2$ and EGR1 genes) and six pro-angiogenesis-related genes that were downregulated (HoxA7, L1Cam, MMP11, RHOT1, VEGF, and Pbx1 genes). Interestingly, a few tumor suppressor genes (e.g., LIF, NPPB, PPAR- $\gamma 2$, and EGR1) and oncogenic genes (e.g. HoxA7, L1cam, and MMP11) showed differences in expression upon 24-MCF treatment, implying that 24-MCF treatment can inhibit the activation of angiogenesis for tumor progression [29].

Angiogenesis is tightly regulated at the molecular level [30]. The imbalance of pro- and anti-angiogenic signaling within tumors creates an abnormal vascular network that is characterized by dilated, tortuous and hyperpermeable vessels [30]. Based on our results, we propose that 24-MCF induces PPAR- $\gamma 2$ to function as an angiogenic switch that mediates the balance between pro- and anti-angiogenic molecular levels [Figure 5]. We identified the presence of PPAR- $\gamma 2$ binding regions in VEGF, LIF, and HoxA7 promoter sequences, and our luciferase assays showed PPAR- $\gamma 2$ decreased activation of the promoters of VEGF and HoxA7, both known pro-angiogenic genes, while the activation of LIF promoter, an anti-angiogenic gene, increased with 24-MCF and PPAR- $\gamma 2$ overexpression, indicating that PPAR- $\gamma 2$ regulates 24MCF-mediated angiogenesis-related genes. These results are consistent with the results of previous studies showing that PPAR- $\gamma 2$ is involved in transcription regulation of genes upon either activation or repression by ligand [4, 27, 31 and 32]. 


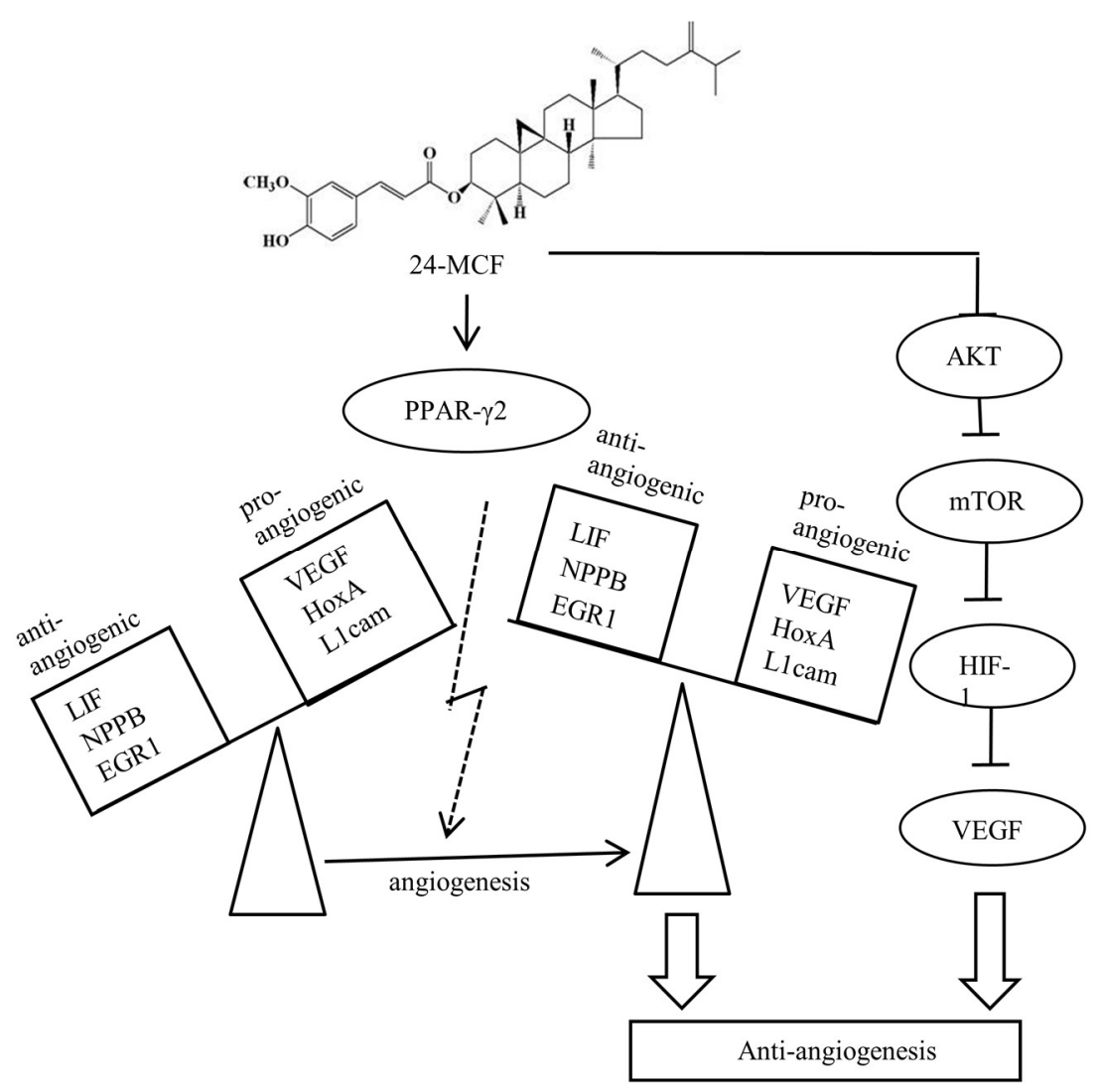

Figure 5. The proposed mechanism by which 24-MCF treatment induces PPAR- $\gamma 2$ mediated anti-angiogenesis. $24-\mathrm{MCF}$ induces PPAR- $\gamma 2$ to function as an angiogenic switch. Induction of PPAR- $\gamma 2$ upregulates anti-angiogenic genes LIF, NPPB and EGR1 thereby inhibiting angiogenesis. Inhibition of Akt/mTOR pathway by 24-MCF treatment effectively suppresses HIF-1 and VEGF expression, thereby inhibiting angiogenesis.

$\mathrm{PI} 3 \mathrm{~K} / \mathrm{Akt} / \mathrm{mTOR}$ pathway also behaves as an angiogenesis inducer involved in VEGF expression [21]. Akt is a central signaling molecule in regulating cell survival, proliferation, tumor growth and angiogenesis [21]. 24-MCF treatment also affected the Akt/mTOR pathway and VEGF expression in MCF7 cells. These results are consistent with our previous results showing that 24-MCF inhibited Akt kinase activity in a cell-free system and docking evidence using the X-ray crystal structure of human Akt protein (PDB ID: 3OCB) [4]. Our ELISA results showed that VEGF secretion was decreased in MCF7 cells treated with 24-MCF. Based on previous studies that displayed PMA-induced angiogenesis is VEGF-dependent [33], we 
analyzed the ability of HUVECs to undergo cell tube formation in response to 24-MCF treatment and found that PMA-induced tube formation of HUVEC cells was markedly attenuated by 24MCF treatment. These results are consistent with previous results showing that VEGF can regulate all of the key steps of the angiogenic process, including proliferation, migration, and tube formation [34]. Thus, the Akt/mTOR pathway is considered very important for VEGF downstream signaling [35]. Our western blot analysis demonstrated that 24-MCF treatment reduced Akt/mTOR signaling (Figure 4A). Together this suggests a model by which VEGF secretion and tube formation is attenuated by $24-\mathrm{MCF}$ by blocking the Akt signaling pathway.

In conclusion, our microarray analysis of MCF7 cells treated with 24-MCF identified 15 differentially expressed genes correlated with angiogenesis. 24-MCF treatment inhibited the Akt/mTOR pathway, concomitant with decreased VEGF secretion and tube formation. Together, this suggests that 24-MCF may be a new anti-angiogenic agent that could be important for the development of new cancer therapeutics in the future.

Author Contributions: J.H.P., G.K.L. conceived and designed, performed experiments, and wrote the paper. J.B.K., H-Y.K., Y.M.Y., H.W.K., H.H.J., S.H.L. and S.H.L performed experiments and analyzed the data.

Funding: This research received no external funding.

Acknowledgements: This work was carried out with the support of "Cooperative Research

Program for Agriculture Science \& Technology Development (Project No.01178704)"

Rural Development Administration, Republic of Korea.

Conflicts of Interest: The authors declare no conflict of interest.

\section{References}

1. Purushothama, S.; Raina, P.L.; Hariharan, K. Effect of long-term feeding of rice bran oil upon lipids and lipoproteins in rats. Mol. Cell.Biochem. 1995, 146, 63-69.

2. Sakamoto, K.; Tabata, T.; Shirasaki, K.; Inagaki, T.; Nakayama, S. Effects of gammaoryzanol and cycloartenol ferulic acid ester on cholesterol diet induced hyperlipidemia in rats. Jpn J Pharmacol. 1987, 45, 559-565. 
3. Seetharamaiah, G.S.; Krishnakantha TP.; Chandrasekhara, N. Influence of oryzanol on platelet aggregation in rats. J. Nutr. Sci. Vitaminol. 1990, 36, 291-297.

4. Kim, H.W; Lim, E.J.; Jang, H.H.; Kang,D.R.; Lee, S.H.; Kim, H.R.; Choe, J.S.; Yang, Y.M.; Kim, J.B.; Park, J.H. 24-Methylenecycloartanyl ferulate, a major compound of $\gamma$-oryzanol, promotes parvin- $\beta$ expression through an interaction with peroxisome proliferator-activated receptor- $\gamma 2$ in human breast cancer cells. Biochem. Biophys. Res. Commun. 2015, 468, 574579.

5. Kong, C.K.; Lam, W.S.; Chiu, L.C.; Ooi, V.E.; Sun, S.S.; Wong, Y.S. A rice bran polyphenol, cycloartenyl ferulate, elicits apoptosis in human colorectal adenocarcinoma SW480 and sensitizes metastatic SW620 cells to TRAIL-induced apoptosis. Biochem. Pharmacol. 2009 77(9), 1487-1496.

6. Kim, S.P.; Kang. M.Y.; Nam, S.H.; Friedman, M. Dietary rice bran component $\gamma-$ oryzanol inhibits tumor growth in tumor-bearing mice, Mol. Nutr. Food Res. 2012, 56(6), 935-944.

7. Panigrahy, D.; Huang, S.; Kieran, M.W.; Kaipainen, A. PPAR $\gamma$ as a therapeutic target for tumor angiogenesis and metastasis. Cancer Biology \& Therapy. 2005, 4:7, 687-693.

8. Gulick, T.; Cresci, S.; Caira, T.; Moore, D.D.; Kelly, D.P. The peroxisome proliferatoractivated receptor regulates mitochondrial fatty acid oxidative enzyme gene expression. 1994, Proc. Natl. Acad. Sci. 91, 11012-11016.

9. Keller, H.; Dreyer, C.; Medin, J.; Mahfoudi, A.; Ozato, K.; Wahli, W. Fatty acids and retinoids control lipid metabolism through activation of peroxisome proliferator-activated receptor-retinoid X receptor heterodimers. 1993, Proc. Natl. Acad. Sci. 90, 2160-2164.

10. Michalik, L.; Auwerx, J.; Berger, J.P.; Chatterjee, V.K.; Glass, C.K.; Gonzalez, F.J.; Grimaldi, P.A.; Kadowaki, T.; Lazar, M.A.; O’Rahilly, S. International Union of Pharmacology. LXI. Peroxisome proliferator-activated receptors. Pharmacol. Rev. 2006, 58, 726-741.

11. Tachibana, K.; Kobayashi, Y.; Tanaka, T.; Tagami, M.; Sugiyama, A.; Katayama, T.; Ueda, C.; Yamasaki, D.; Ishimoto, K.; Sumitomo, M.; Uchiyama, $\quad$ Y.; Kohro, T.; Sakai, J.; Hamakubo, T.; Kodama, T.; Doi, T. Gene expression profiling of potential peroxisome proliferator-activated receptor (PPAR) target genes in human hepatoblastoma cell lines inducibly expressing different PPAR isoforms. Nucl. Recept. 2005, 3, 1-17.

12. Tontonoz, P.; Hu, E.; Graves, R.A.; Budavari, A.I.; Spiegelman, B.M.; mPPAR gamma 2: tissue-specific regulator of an adipocyte enhancer. Genes Dev. 1994, 8(10), 1224-1234. 
13. Tonini, T.; Rossi, F.; Claudio, P.P. Molecular basis of angiogenesis and cancer. Oncogene, 2003, 22, 6549-6565.

14. Xin, X.; Yang, S.; Kowalski, J.; Gerritsen, M.E. Peroxisome proliferator-activated receptor $\gamma$ ligands are potent inhibitors of angiogenesis in vitro and in vivo. J. Biol. Chem. 1999, 274, 9116-9121.

15. Bishop-Bailey D. PPARs and angiogenesis. Biochem. Soc. Trans. 2011, 39(6), 1601-1605.

16. Venkatachalam, G.; Kumar, A.P.; Yue, L.S.; Pervaiz, S.; Clement, M. V.; Sakharkar, M.K. Computational identification and experimental validation of PPRE motifs in NHE1 and MnSOD genes of human. BMC Genomics 2009, 10(Suppl 3):S5, 1-13.

17. Wang, L.; Waltenberger, B.; Pferschy-Wenzig, E.M.; Blunder, M.; Liu, X.; Malainer, C.; Blazevic, T.; Schwaiger, S.; Rollinger, J.M.; Heiss, E.H.; Schuster, D.; Kopp, B.; Bauer, R.; Stuppner, H.; Dirsch, V.M.; Atanasov, A.G. Natural product agonists of peroxisome proliferator-activated receptor gamma (PPAR $\gamma$ ). Biochem. Pharmacology 2014, 92(1), 73-89.

18. Hanahan, D., Folkman, J., Patterns and emerging mechanisms of the angiogenic switch during tumorigenesis. Cell 1996, 86(3), 353-364.

19. Abdollahi, A.; Schwager, C.; Kleeff, J.; Esposito, I.; Domhan, S.; Peschke, P.; Hauser, K.; Hahnfeldt, P.; Hlatky, L.; Debus, J.; Peters, J.M.; Friess, H.; Folkman, J.; Huber, P.E. Transcriptional network governing the angiogenic switch in human pancreatic cancer. Proc. Natl. Acad. Sci. 2007, 104(31), 12890-12895.

20. Heinäniemi, M.; Carlberg, C. Screening for PPAR Responsive Regulatory Modules in Cancer. PPAR Research 2008, 1-8.

21. Fang, J.; Xia, C.; Cao, Z.; Zheng J.Z.; Reed, E.; Jiang B-H. Apigenin inhibits VEGF and HIF-1 expression via PI3K/AKT/p70S6K1 and HDM2/p53 pathways. FASEB J. 2015, 19, 342-353.

22. Karar, J.; Maity, A. PI3K/AKT/mTOR Pathway in Angiogenesis. Front Mol. Neurosci. 2011, $4: 51,1-8$.

23. Bergers, G.; Benjamin, L.E. Tumorigenesis and the angiogenic switch. Nat. Rev. Cancer 2003, 3(6), 401-410.

24. Han, S.W.; Roman, J. Anticancer actions of PPAR $\gamma$ ligands: Current state and future perspectives in human lung cancer. World J. Biol. Chem. 2010, 1(3), 31-40. 
25. Grommes, C.; Landreth, G.E.; Heneka, M.T.; Antineoplastic effects of peroxisome proliferator-activated receptor gamma agonists. Lancet Oncol. 2004, 5, 419-429.

26. Keshamouni, V. G.; Arenberg, D.A.; Reddy, R.C.; Newstead, M. J.; Anthwal, S.; Standiford, T.J. PPAR- $\gamma$ Activation Inhibits Angiogenesis by Blocking ELR + CXC Chemokine Production in Non-small Cell Lung Cancer. Neoplasia 2005, 7(3), 294-301.

27. Nava-Villalba, M., Nuñez-Anita, R.E., Bontempo, A., Aceves, C., Activation of peroxisome proliferator-activated receptor gamma is crucial for antitumoral effects of 6-iodolactone. Mol. Cancer 2015, 14 (168), 1-11.

28. Yasukawa, K.; Akihisa, T.; Kimura, Y.; Tamura, T.; Takido M. Inhibitory effect of cycloartenol ferulate, a component of rice bran, on tumor promotion in two-stage carcinogenesis in mouse skin. Biol. Pharm. Bull. 1998, 21(10), 1072-1076.

29. Stockmann, C.; Schadendorf, D.; Klose, R.; Helfrich I. The impact of the immune system on tumor: angiogenesis and vascular remodeling. Frontier in Ocology 2014, 4(69), 1-13.

30. Goel, S.; Duda, D.G.; Xu, L.; Munn, L.L.; Boucher, Y.; Fukumura, D.; Jain, R.K. Normalization of the vasculature for treatment of cancer and other diseases. Physiol. Rev. 2011, 91(3), 1071-1121.

31. Ricote, M.; Li, A.C.; Willson, T.M.; Kelly, C.J.; Glass, C.K. The peroxisome proliferatoractivated receptor-gamma is a negative regulator of macrophage activation. Nature 1998. 391(6662), 79-82.

32. Barak, Y.; Nelson, M.C.; Ong, E.S.; Jones, Y.Z.; Ruiz-Lozano, P.; Chien, K.R.; Koder, A.; Evans, R.M. PPAR gamma is required for placental, cardiac, and adipose tissue development. Mol. Cell. 1999, 4(4), 585-595.

33. Xu, H.; Czerwinski, P.; Hortmann, M.; Sohn, H.Y.; Förstermann, U.; Li, H. Protein kinase $\mathrm{C}$ alpha promotes angiogenic activity of human endothelial cells via induction of vascular endothelial growth factor. Cardiovasc. Res. 2008, 78(2), 349-355.

34. Pan, Y.; Wu, Q.; Qin, L.; Cai, J.; Du, B. Gold nanoparticles inhibit VEGF165-induced migration and tube formation of endothelial cells via the Akt pathway. Biomed Res. Int. 2014, $1-11$.

35. Graupera, M.; Potente, M. Regulation of angiogenesis by PI3K signalling networks. Experimental Cell Research 2013, 319(9), 1348-1355.

36. Pepper, M.S.; Ferrara, N.; Orci, L.; Montesano, R. Leukemia inhibitory factor (LIF) inhibits angiogenesis in vitro. J. cell sci. 1995, 108, 73-83. 
37. Manolopoulos, V.G.; Liekens, S.; Koolwijk, P.; Voets, T.; Peters, E.; Droogmans, G.; Lelkes P.I.; De Clercq, E.; Nilius, B. Inhibition of angiogenesis by blockers of volume-regulated anion channels. Gen. Pharmacol. 2000, 34(2), 107-116.

38. Kozulin, P.; Natoli, R.; O'Brien K.M.; Madigan, M.C.; Provis, J.M. Differential expression of anti-angiogenic factors and guidance genes in the developing macula. Mol. Vis. 2009, 15, 45-59.

39. Lucerna, M.; Pomyje, J.; Mechtcheriakova, D.; Kadl, A.; Gruber, F.; Bilban, M.; Sobanov, Y.; Schabbauer, G.; Breuss, J.; Wagner, O.; Bischoff, M.; Clauss, M.; Binder, B.R.; Hofer, E. Sustained expression of early growth response protein-1 blocks angiogenesis and tumor growth. Cancer Res. 2006, 66(13), 6708-6713.

40. Tang, B.; Qi, G.; Sun, X.; Tang, F.; Yuan, S.; Wang, Z.; Liang, X.; Li, B.; Yu, S.; Liu, J.; Huang, Q.; Wei, Y.; Zhai, R.; Lei, B.; Guo, X.; He, S.; HoxA7 plays a critical role in metastasis of liver cancer associated with activation of Snail. Mol. Cancer 2016, 15(1), 1-12.

41. Kelly, Z.L.; Michael, A.; Butler-Manuel, S.; Pandha, H.S.; Morgan, R.G. HOX genes in ovarian cancer. J. Ovarian Res. 2011, 4:16, 1-6.

42. Chen, D.L.; Zeng, Z.L.; Yang, J.; Ren, C.; Wang, D.S.; Wu, W.J.; Xu, R.H. L1cam promotes tumor progression and metastasis and is an independent unfavorable prognostic factor in gastric cancer. J. Hematol. Oncol. 2013, 6:43, 1-13.

43. Magrini, E.; Villa, A.; Angiolini, F.; Doni, A.; Mazzarol, G.; Rudini, N.; Maddaluno, L.; Komuta, M.; Topal, B.; Prenen, H.; Schachner, M.; Confalonieri, S.; Dejana, E.; Bianchi, F.; Mazzone, M.; Cavallaro, U. Endothelial deficiency of L1 reduces tumor angiogenesis and promotes vessel normalization. J. Clin. Invest. 2014, 124(10), 4335-4350.

44. Sunil Kumar, B.V.; Kumar, K.A.; Padmanath, K.; Sharma, B.; Kataria, M. Heterologous expression and functional characterization of matrix metalloproteinase-11 from canine mammary tumor. Anim. Biotechnol. 2013, 24(1), 31-43.

45. Li, Q.; Yao, L.; Wei, Y.; Geng, S.; He, C.; Jiang, H. Role of RHOT1 on migration and proliferation of pancreatic cancer. Am, J. Cancer Res. 2015, 5(4), 1460-1470.

46. Schwarte-Waldhoff, I.; Schmiegel, W. SMAD4 transcriptional pathways and angiogenesis. Int. J. Gastrointest. Cancer 2002, 31(1-3), 47-59.

47. Charboneau, A.; East, L.; Mulholland, N.; Rohde, M.; Boudreau, N.; Pbx1 is required for Hox D3-mediated angiogenesis. Angiogenesis 2005, 8(4), 289-296. 